\title{
THE EFFECT OF A MODIFIED FRAGMENT OF NEUROPEPTIDE Y ON SPATIAL MEMORY AND LEARNING IN THE MORRIS WATER MAZE
}

\author{
Ihnat Havrylov, Sergiy Shtrygol’, Dmytryi Kavraiskyi
}

Neuropeptide Y (NPY) is a biologically active neuropeptide that is responsible for a large list of physiological processes. We propose a short modified fragment of NPY that should at least partially have a spectrum of biological activity of the original peptide. The compound was named nonapeptide NP9.

The aim of our study was to investigate the ability of the modified fragment of NPY to influence spatial memory and learning.

Materials and methods: the study was performed on 24 one-year-old random-bred female rats weight 220-250 g. The animals were divided into 3 groups of 8 rats each: treated with a solvent $(0.9 \% \mathrm{NaCl})$, a solution of peptide NP9 $0.02 \mathrm{mg} / \mathrm{kg}$ and the drug "Semax" $0.1 \mathrm{mg} / \mathrm{kg}$. All drugs were administered intranasally. The study of the effect of the peptide NP9 on spatial memory and learning ability was performed in the psychopharmacological test the Morris water maze. Navigation parameters were analyzed using Noldus EthoVision XT 14 video tracking software. The escape latency, the distance moved, the average velocity and the meander were recorded. An inter-quadrant analysis of rat behavior was also performed, for which the frequency of appearance and time spent in certain quadrants were recorded.

Results: nonapeptide NP9 in the Morris water maze test demonstrated the ability to accelerate the time to find a hidden platform, reduce the distance traveled, meander, and optimize the search strategy.

Conclusions: NP9 peptide has demonstrated the ability to positively influence learning and spatial memory. The improvement in cognitive performance of animals administered with the peptide NP9 was no less than that of the reference nootropic drug Semax. These results substantiate the feasibility of further research with the aim of pharmaceutical development of a new nootropic drug

Keywords: modified fragment of neuropeptide $Y$, the Morris water maze, spatial memory, learning

How to cite:

Havrylov, I., Shtrygol', S., Kavraiskyi, D. (2022). The effect of a modified fragment of neuropeptide Y on spatial memory and learning in the Morris water maze. ScienceRise: Pharmaceutical Science, 1 (35), 22-27. doi: http://doi.org/10.15587/2519-4852.2022.253372

(C) The Author(s) 2022

This is an open access article under the Creative Commons CC BY license hydrate

\section{Introduction}

Mental and neurological disorders are an urgent problem. Their prevalence has increased by $16 \%$ in recent years, with further growth expected due to population aging and the impact of adverse factors such as armed conflict and migration [1]. Political and military crises contribute to the mass displacement of the population. The number of internally displaced persons increased from 33.9 million in 1997 to 79.5 million in 2019, including 2.1 million Ukrainian citizens who have been forced to leave their place of residence due to the Russian aggression that has been going on since 2014 [2]. The prevalence of depression, anxiety and cognitive disorders among refugees is at least three times higher than in the general population [3]. The pharmacotherapy of these disorders is often ineffective and is almost always associated with a variety of adverse reactions [4] and therefore needs to be reviewed and improved. In this aspect, multifunctional products of peptide design attract attention. The vast majority of peptide drugs are designed to treat metabolic or immunological disorders [5]. Some drugs of peptide structure are used in diseases of CNS. Examples are "Cerebrolysin" (EVER Neuro Pharma $\mathrm{GmbH}$, Austria) contains low molecular weight biologi- cally active neuropeptides from the brain of pigs, has a normalizing effect on cognitive impairment, improves memory [6], "Cortexin" (Geropharm, Russia), "Cortagen" (Geropharm, Russia), "Semax" (Peptogen, Russia), "Selank" (Peptogen, Russia), "Noopept" (Otisipharm, Russia) [7]. Despite long experience in the use of peptidergic drugs for the treatment of CNS disorders, the question of their clinical effectiveness remains open. The range of such drugs in Ukraine is small. Therefore, further search and proof of the effectiveness of new peptide agents for the treatment of CNS disorders is an urgent task.

Neuropeptide Y (NPY) is a biologically active peptide that is one of the most abundant neurotransmitters in the central and peripheral nervous systems. In humans, it is able to activate 4 types of its own Yreceptors (Y1, Y2, Y4 and Y5), which are responsible for various processes, and their expression occurs in many parts of the central nervous system. They are known to play an important role in the regulation of food consumption, energy homeostasis, circadian rhythms, stress response, etc [8].

The most thoroughly studied NPY receptors are now Y1 and Y2. It is known that they are most expressed 
in the cerebral cortex, amygdala, hippocampus, hypothalamus. These are areas of the brain that play an important role in learning and memory [9]. In the review Gøtzsche et al. [10] states that NPY exhibits the ability to modulate neuroplasticity, synaptic transmission, and affect certain types of memory. The effects on memory can be both stimulatory and inhibitory depending on the dose of NPY, the neuroanatomical sites and subtypes of the receptors it affects, and the phase of memory during which it is administered [10]. Many studies point to the interrelated effects of NPY on memory processes and the regulation of the stress response [10-12].

Suppression of fear conditioning, facilitates extinction of negative emotional experiences, which occurs due to the simultaneous action on Y1- and Y2-receptors [12], affects the body's resilience to stress, prevents emotional exhaustion. NPY also improves the consolidation and retention of non-social memory by acting on Y1 receptors, and could improve the retrieval of social memory through both Y1 and Y2 receptors [13]. NPY and $\mathrm{Y} 1$ receptor agonists have been found to improve memory in a model of Alzheimer's disease [14]. The exogenous NPY, acting on the Y2-receptors impairs acquisition and spatial memory consolidation, but increases the expression of NPY gene and through Y1receptor - neurogenesis, presumably necessary for longterm retention [10]. The important effect of Y2-receptors on spatial memory and learning is confirmed by the fact that Y2-receptor antagonists, in contrast, have a positive effect on learning in the Morris water maze [9]. In other experiments, NPY blocked the amnestic effect of colchicine [14], anisomycin, scopolamine [15] and disocylpine (MK-801) [16].

Therefore, the actual problem could be considered investigation of the activity of low molecular weight, preferably selective ligands of certain types of NPY receptors, which contributes to a better understanding of NPY system and necessary for relevant pharmaceutical development [17]. The original neuropeptide Y molecule consists of 36 amino acid residues. We offer its shortened modified fragment, which, in contrast to the original peptide, consists of 9 amino acid residues. This makes the peptide cheaper and easier to manufacture, and therefore more acceptable for further implementation. It is known that the C-terminal region of NPY is responsible for binding to receptors [18], therefore we proposed an amino acid sequence H-L-Ile-L-Asn-L-Leu-L-Nle-LSer-L-Arg-L-Asn-L-Arg-L-Tyr- $\mathrm{NH}_{2}$ as a modified Cterminal fragment of NPY. Amino acid substitutions at positions 4,5 , and 7 should not disrupt the tertiary structure and affect binding to NPY receptors, it is also possible that they could reduce the rate of peptide proteolysis [19]. Thus, the object of our study was a modified fragment of human NPY, what received the laboratory code "nonapeptide NP9". The peptide NP9 must at least partially exhibit a spectrum of biological activity characteristic of NPY, which can be useful in the treatment of cognitive and anxiety disorders. But it is possible that, like the original peptide, NP9 may have other mechanisms of action and pharmacological effects that are not related to the NPY system. Previous studies have shown the presence of high anxiolytic [20] and nootropic [21] properties of NP9.
The aim of our study was to investigate the ability of the modified fragment of NPY to influence spatial memory and learning.

\section{Planning (methodology) of research}

Taking into account the results of previous studies [21] and the ability of NPY affect memory and learning, our aim was to test the presence of the corresponding properties in its modified derivative - NP9, in particular, the effect on spatial memory and learning.

In addition to economic benefits, the shorter amino acid sequence and consequently lower molecular weight (1148 Da) determine the potential pharmacokinetic benefits of NP9, as it suggests the ability to transneuronal transport in brain neurons by intranasal (i.n.) administration. Considering the literature sources that indicate the ability of the NPY molecule to enter the brain in 30 minutes [22], it is logical to assume no worse bioavailability of its shorter analogue. Therefore, the intranasal route of administration of NP9 is selected. This prevents the rapid destruction of the peptide by proteases from the stomach, blood serum, etc. It also allows the peptide to enter the CNS directly, bypassing the blood-brain barrier, what leads to high cerebral bioavailability and a decrease in the side effects on peripheral organs [23].

The Morris water maze (MWM) test was used to assess the effect of nonapeptide NP9 on spatial memory and learning [24-26].

Stages that were used:

1. Literary sources analysis;

2. Preparation of all equipment, setting up video camera and video tracking software;

3. Grouping of animals;

4. Give the case groups the prescribed doses;

5. Training of animals;

6. Probe trial;

7. Obtained data analysis.

\section{Materials and methods}

\subsection{Materials}

Based on our order the nonapeptide NP9 was synthesized by Shanghai Apeptide Co., Ltd. (China). Quality test was performed by two methods (high performance liquid chromatography and chromatography coupled to MS spectroscopy) and showed $99 \%$ of purity. A freshly prepared solution of the NP9 peptide was used at a dose of $0.02 \mathrm{mg} / \mathrm{kg}$ for rats. For this, the NP9 substance was dissolved in a $0.9 \% \mathrm{NaCl}$ solution so as to provide the required concentration when administered in a volume of $0.02 \mathrm{ml}$ i.n. For i.n. administration, an insulin syringe with a blunt needle was used.

As a reference drug was used "Semax" (Peptogen, Russia) at a dose of $0.1 \mathrm{mg} / \mathrm{kg}$, i.n. This heptapeptide (Met-Glu-His-Phe-Pro-Gly-Pro) is a synthetic analogue of $\mathrm{ACTH}_{4-10}$. The criteria for selection of the reference drug were peptide structure, positive effects on cognitive functions and i.n. route of administration [27].

\subsection{Methods}

\subsubsection{Study design}

The equipment for the Morris water maze consisted of a circular pool $(120 \mathrm{~cm}$ in diameter and $55 \mathrm{~cm}$ in height) filled with water $\left(26 \pm 1^{\circ} \mathrm{C}\right)$ to $45 \mathrm{~cm}$. At equal 
distances from each other along the edge of the pool were located 8 different plastic colored cues (external landmarks). The perimeter of the pool was marked in accordance with the cardinal direction $(\mathrm{N}, \mathrm{E}, \mathrm{S}, \mathrm{W})$, what conditionally delimited it into 4 equal quadrants: northwestern (NW), northeastern (NE), southwestern (SW), southeastern (SE). In a fixed position in the SW quadrant was the escape platform ( $9 \mathrm{~cm}$ in diameter). During training session, the platform was $1.5 \mathrm{~cm}$ above the surface of the water.

For two consecutive days, the animals received drugs and solvent and trained to find a platform. For this, the animals three times (from different positions) each day were placed in the pool (facing pool wall) for $60 \mathrm{~s}$. The starting points was chosen 3 distal equidistant from the platform positions at the walls of the pool - N, NE, E. On the first day, the animals were sequentially placed from the position in the clockwise direction (from $\mathrm{N}$ ), in the second - anti (from E). The interval between a training trials on one day was approximately $120 \mathrm{~s}$. The animals that were unable to find the platform within 60 seconds, were set on the platform for 20 seconds. The animals that independently found the platform remained on it for $15 \mathrm{~s}$.

On the third day, a probe trial was performed. The platform was immersed $1 \mathrm{~cm}$ below the water level. The water was made opaque with powdered milk. Video tracing was performed using a video camera (TRUST Viveo HD 720P) located above the pool. Navigation parameters were analyzed using Noldus EthoVision XT 14 video trakcing software. The animals began the test from the NE quadrant. The escape latency, the distance moved, the average velocity and the meander were recorded. An inter-quadrant analysis of rat behavior was also performed, for which the frequency of appearance and time spent in certain quadrants were recorded. The percentage of time spent in the quadrant of total time was calculated using the formula:

$$
\%=\frac{\sum \text { time spent in the qudrant }}{\text { latency time }} \times 100 \%
$$

\subsubsection{Experimental animals and grouping}

Studies in the MWM test were performed on oneyear-old random-bred female rats weight $220-250 \mathrm{~g}$. The animals were obtained from the vivarium of the Central Research Laboratory (National University of Pharmacy, Kharkiv, Ukraine). The preclinical study was also conducted there. Experiments were carried out in accordance with the U.K. Animals (Scientific Procedures) Act, 1986 and "Directive 2010/63/EU of the European Parliament and of the Council of 22 September 2010 on the protection of animals used for scientific purposes". The animals were housed in standard polypropylene cages and kept at $20-26^{\circ} \mathrm{C}$ and $50 \%$ humidity in a well-ventilated room with a $12 \mathrm{~h}$ light/dark cycle with free access to food and water. All experimental protocols were approved by the Bioethics Commission of the National University of Pharmacy (Protocol No 3 of 20 March 2019, Kharkiv, Ukraine).

The animals were divided into 3 groups of 8 rats each. Group 1 - animals intact control, treated with saline i.n.; Group 2 - animals treated with solution of peptide NP9
$0.02 \mathrm{mg} / \mathrm{kg}$ i.n.; Group 3 - animals treated drug "Semax" $0.1 \mathrm{mg} / \mathrm{kg}$ i.n. All drugs were administered for two consecutive days 30-35 minutes before training session.

\subsubsection{Statistical analysis}

MS Excel 2016 and STATISTICA v.12 software were used for calculations. Analysis of the data ranges using the Kolmogorov-Smirnov test and the Shapiro-Wilk normality test showed that there was sufficient evidence to reject the notion of a normal probability model. All obtained results were processed using descriptive statistics and presented as $\mathrm{M} \pm \mathrm{SD}, \mathrm{Me}\left(\mathrm{Q}_{1} ; \mathrm{Q}_{3}\right)$ or in percentage terms. The statistical difference between the groups was determined using Mann-Whitney $U$ test. In inter-quadrant analysis, intragroup differences were identified using the Wilcoxon test. Intergroup differences in the time spent in the quadrant (after recalculating in percent) were determined using the Mann-Whitney test. The differences were considered statistically significant at $\mathrm{p}<0.05$.

\section{Results}

The results of the experiment show that animals that received both drugs (NP9, "Semax") better remembered the location of the platform. These conclusions are based on the results of the study (Table 1). The time spent by animals to search for the platform decreased (for the peptide NP9 group - by $32.9 \%$, for the "Semax" group - by $50.8 \%$ ). The escape latency is an important parameter, but it could lead to erroneous conclusions, because it significantly depends on the velocity of the animals. The velocity of rats of the "Semax" group did not change significantly, while in animals of the peptide NP9 group it decreased by $20.2 \%$. In addition, the length of the path that the animals traveled in search of the platform has decreased (for the peptide NP9 - by $63.2 \%$, $\mathrm{p}<0.05$, for "Semax" - by $59.0 \%$ ). This may mean that the animals of the peptide NP9 group remembered the location of the platform no worse than the animals of the "Semax" group, because they traveled the distance about the same, and spent more time searching for the platform due to the lower swimming speed. A lower velocity may additionally indicate decreased anxiety of animals or an energy-saving search strategy. The meander characterizes the tortuosity of the trajectory of movement, and the degree of its change, in a certain sense, meant the confidence of animals in the chosen trajectory of movement. The analysis shows that the animals moved more confidently, as in the NP9 group the meander decreased by $57.7 \%(\mathrm{p}<0.01)$, and in the "Semax" group - by $66.0 \%$ $(\mathrm{p}<0.01)$.

The results of inter-quadrant analysis (Table 2) allow not only to identify the presence of memories of the location of the platform, but also to assess the search strategy, its direction.

All animals more often appeared in the NE quadrant, while other quadrants visited approximately equally. As indicated in the method, the test was started from the NE quadrant, and the researcher was also located nearby, which from the previous experience of the animals, rescued them from the pool. This probably influenced the final preference for this quadrant. But the animals of the peptide NP9 group did not linger in the starting NE quadrant. As a result, they spent 
more time in the target SW quadrant and less in the starting quadrant, what we see when comparing with control group (by 2.8 and 1.9 times, respectively, $\mathrm{p}<0.01$ ) and with animals of the "Semax" group (by 1.3 and 1.4 times, respectively, $\mathrm{p}<0.05)$. Animals of the "Semax" group also showed a significantly longer duration of time spent in the target quadrant $(\mathrm{p}<0.01)$ and less in the start $(\mathrm{p}<0.05)$ relative to the control, but no statistically significant difference was found when comparing intragroup preferences, whereas rats of the nonapeptide NP9 group significantly 2.1 times more time was spent in the target quadrant than in the starting one $(\mathrm{p}<0.05)$.

Table 1

Effects of NP9 and "Semax" on spatial memory and learning in the Morris water maze; $\pm \mathrm{SD}, \mathrm{Me}\left(\mathrm{Q}_{1} ; \mathrm{Q}_{3}\right)$

\begin{tabular}{|c|c|c|c|c|}
\hline Group, $\mathrm{n}$ & Escape latency, $\mathrm{s}$ & Distance moved, cm & Velocity, cm/s & Meander, degree/cm \\
\hline \multirow{2}{*}{ Vehicle control, $(\mathrm{n}=8)$} & $85.0 \pm 63.4$ & $1670.0 \pm 1184.6$ & $21.8 \pm 6.7$ & $38.3 \pm 10.4$ \\
& $74[33 ; 136]$ & $1706[552 ; 2340]$ & $20[18 ; 26]$ & $40[34 ; 46]$ \\
\hline \multirow{2}{*}{$\mathrm{NP9}, 0.02 \mathrm{mg} / \mathrm{kg},(\mathrm{n}=8)$} & $57.0 \pm 41.8$ & $614.7 \pm 463.5^{*}$ & $17.4 \pm 4.9$ & $16.2 \pm 11.6^{* *}$ \\
& $54[26 ; 73]$ & $501[275 ; 911]$ & $17[15 ; 21]$ & $13[8 ; 20]$ \\
\hline \multirow{2}{*}{ Semax, $0.1 \mathrm{mg} / \mathrm{kg},(\mathrm{n}=8)$} & $41.9 \pm 31.7$ & $685.2 \pm 636.0$ & $23.2 \pm 8.0$ & $13.0 \pm 7.4^{* *}$ \\
& $35[16 ; 64]$ & $515[262 ; 920]$ & $21[19 ; 27]$ & $15[6 ; 19]$ \\
\hline
\end{tabular}

Note: statistical significant differences. Relative to the vehicle controle group: $*-p<0.05 ; * *-p<0.01 . n-$ number of animals in the experiment

Table 2

The inter-quadrant analysis of the behavior of animals in the Morris water maze; $M \pm S D, M e\left(Q_{1} ; Q_{3}\right)$

\begin{tabular}{|c|c|c|c|c|c|}
\hline Group, $\mathrm{n}$ & Parameter & $\begin{array}{c}\text { SW } \\
\text { (Platform) }\end{array}$ & SE & NW & $\begin{array}{c}\mathrm{NE} \\
(\text { Start })\end{array}$ \\
\hline \multirow{3}{*}{ Vehicle control, $(n=8)$} & Time spent, s & $\begin{array}{c}10.7 \pm 6.4 \\
10[7 ; 13]\end{array}$ & $\begin{array}{c}19.4 \pm 14.2^{\mathrm{B}} \\
22[5 ; 31]\end{array}$ & $\begin{array}{c}16.0 \pm 14.2 \\
14.2[7 ; 18]\end{array}$ & $\begin{array}{l}35.2 \pm 33.4^{\mathrm{ABC}} \\
25.8[13 ; 48]\end{array}$ \\
\hline & Percentage of time, $\%$ & $\begin{array}{c}15.4 \pm 5.6 \\
15[14 ; 19]\end{array}$ & $\begin{array}{c}23.1 \pm 9.6 \\
23[21 ; 30]\end{array}$ & $\begin{array}{c}20.3 \pm 10.7 \\
21[11 ; 26]\end{array}$ & $\begin{array}{c}38.0 \pm 12.1^{\mathrm{ABC}} \\
35[31 ; 45]\end{array}$ \\
\hline & Frequency of appearance & $\begin{array}{l}4.5 \pm 3.1 \\
4[3 ; 6]\end{array}$ & $\begin{array}{c}6.6 \pm 4.7 \\
7[2 ; 11]\end{array}$ & $\begin{array}{c}4.8 \pm 4.0^{\mathrm{B}} \\
4[1 ; 6]\end{array}$ & $\begin{array}{c}7.5 \pm 5.9 \\
8[2 ; 12]\end{array}$ \\
\hline \multirow{3}{*}{$\mathrm{NP} 9,0.02 \mathrm{mg} / \mathrm{kg},(\mathrm{n}=8)$} & Time spent, $\mathrm{s}$ & $\begin{array}{c}24.1 \pm 18.2 \\
22[10 ; 33]\end{array}$ & $\begin{array}{l}13.2 \pm 9.9^{\mathrm{B}} \\
12[6 ; 16]\end{array}$ & $\begin{array}{l}9.2 \pm 2.8^{\mathrm{B}} \\
9[2 ; 16]\end{array}$ & $\begin{array}{c}12.8 \pm 10.5^{\mathrm{AB}} \\
11[5 ; 19]\end{array}$ \\
\hline & Percentage of time, $\%$ & $\begin{array}{c}43.1 \pm 12.5^{* * \#} \\
40[34 ; 55]\end{array}$ & $\begin{array}{c}27.2 \pm 13.0 \\
26[18 ; 35]\end{array}$ & $\begin{array}{l}13.1 \pm 9.7^{\mathrm{B}} \\
15[4 ; 22]\end{array}$ & $\begin{array}{c}20.2 \pm 7.1 * * \#^{\mathrm{AB}} \\
21[15 ; 27]\end{array}$ \\
\hline & Frequency of appearance & $\begin{array}{l}4.3 \pm 2.1 \\
4[3 ; 6]\end{array}$ & $\begin{array}{l}4.7 \pm 4.3 \\
4[2 ; 6]\end{array}$ & $\begin{array}{c}3.0 \pm 1.9^{\mathrm{B}} \\
4[2 ; 4]\end{array}$ & $\begin{array}{c}5.9 \pm 5.1^{\mathrm{A}} \\
5[2 ; 7]\end{array}$ \\
\hline \multirow{3}{*}{ Semax, $0.1 \mathrm{mg} / \mathrm{kg},(\mathrm{n}=8)$} & Time spent, $\mathrm{s}$ & $\begin{array}{l}11.4 \pm 8.3 \\
9[6 ; 15]\end{array}$ & $\begin{array}{l}8.1 \pm 6.6^{\mathrm{B}} \\
8[3 ; 11]\end{array}$ & $\begin{array}{c}8.9 \pm 2.3 \\
10[3 ; 15]\end{array}$ & $\begin{array}{l}12.0 \pm 9.7^{\mathrm{C}} \\
10[4 ; 19]\end{array}$ \\
\hline & Percentage of time, $\%$ & $\begin{array}{c}31.9 \pm 11.2^{* *} \\
31[23 ; 42]\end{array}$ & $\begin{array}{c}18.1 \pm 9.2^{\mathrm{B}} \\
18[15 ; 23]\end{array}$ & $\begin{array}{c}20.8 \pm 11.6 \\
22[15 ; 27]\end{array}$ & $\begin{array}{c}28.1 \pm 5.9^{*} \\
30[25 ; 32]\end{array}$ \\
\hline & Frequency of appearance & $\begin{array}{l}2.9 \pm 2.4 \\
2[2 ; 4]\end{array}$ & $\begin{array}{l}3.3 \pm 3.3 \\
3[1 ; 5]\end{array}$ & $\begin{array}{l}2.9 \pm 2.8 \\
3[1 ; 4]\end{array}$ & $\begin{array}{c}3.9 \pm 3.2^{\mathrm{AC}} \\
4[1 ; 6]\end{array}$ \\
\hline
\end{tabular}

Note: statistical significant differences. Relative to the vehicle controle group: $*-p<0.05 ; * *-p<0.01$; relative to the Semax group: $\#-p<0.05$. Wilcoxon signed-rank test. Relative to $N W: A-p<0.05$; relative to $S W: B-p<0.05$; relative to $S E$ : $C-p<0.05$. $n-$ number of animals in the experiment

\section{Discussion}

The results of the study indicate that nonapeptide NP9 improves spatial memory and learning no worse than the peptide nootropic "Semax". But, in contrast to the reference drug, the search strategy for animals of the peptide NP9 group is aimed more at searching specifically in the target area of the maze. The animals spent more time and studied the external landmarks in the SW quadrant, where the platform was located. NP9 animals also chose an energy-saving search strategy because they moved more slowly, swam shorter distances as a trend, and visited quadrants more often, but did not spend much time on non-target quadrants.

The results of the experiment are consistent with the data of the Méndez-Couz experiments et al. [9], where Y2 receptor antagonists improved platform location memory in the MWM. This suggests that nonapep- tide NP9 belongs to Y2 receptor antagonists. Additionally, this is indicated by the results of previous experiments, which revealed the anxiolytic properties of the peptide [20], and, as is known, Y2-receptor antagonists show the ability to reduce anxiety behavior [28].

Findings shows the presence of nootropic properties of NP9 which are apparently due to the effect on the Y2 receptors. But further in-depth study of nonapeptide NP9 is required for a clear understanding of the exact mechanisms of action of the obtained effects.

Study limitations. Without further study of its biochemical mechanisms of action, it is obviously incorrect to claim that the detected effects are due to exposure only to the NPY system.

Prospects for further research. The results indicate the feasibility of further in-depth study of the nonapeptide NP9 for the development a nootropic drug. 


\section{Conclusion}

A study of the effect of nonapeptide NP9 on spatial memory and learning in rats in the Morris water maze was performed. The results showed that nonapeptide NP9 $(0.02 \mathrm{mg} / \mathrm{kg})$ and the reference drug Semax $(0.1 \mathrm{mg} / \mathrm{kg})$, when administered i.n., significantly improved memory retention in rats in the Morris water maze. The improvement in learning and spatial memory of the animals of the peptide NP9 group was no worse, and in some parameters better than the animals of the group of the reference nootropic "Semax". An inter-quadrant analysis of the search of the platform shows that there is some difference in the search strategy, which is probably due to different mechanisms of influence on memory and learning. The mechanisms by which nonapeptide NP9 could improve cognitive processes are not clearly defined. The mechanisms could be associated with NPY system or other targets. These results substantiate the feasibility of further study of biomarkers of the mechanism of action of NP9 and interaction with Y2 receptors for further pharmaceutical development in order to create a new nootropic drug with additional anxiolytic properties.

\section{Conflicts of interest}

The authors declare that they have no conflicts of interest.

\section{Formatting of funding sources}

The study was performed without financial support.

\section{References}

1. Vos, T., Allen, C., Arora, M., Barber, R. M., Bhutta, Z. A., Brown, A. et. al. (2016). Global, regional, and national incidence, prevalence, and years lived with disability for 310 diseases and injuries, 1990-2015: a systematic analysis for the Global Burden of Disease Study 2015. The Lancet, 388 (10053), 1545-1602. doi: http://doi.org/10.1016/s0140-6736(16)31678-6

2. Global Trends 2019: Forced Displacement in 2019 (2019). UNHCR Flagship Reports. Available at: https://www.unhcr.org/ flagship-reports/globaltrends/globaltrends2019/

3. Migrant populations, including children, at higher risk of mental health disorders (2017). World Health Organization. Available at: from https://www.euro.who.int/en/health-topics/noncommunicable-diseases/mental-health/news/news/2017/04/migrantpopulations,-including-children,-at-higher-risk-of-mental-health-disorders

4. Alcântara, C. B. de, Capistrano, F. C., Czarnobay, J., Ferreira, A. C. Z., Brusamarello, T., Maftum, M. A. (2018). Drug therapy for people with mental disorders in the view of nursing professionals. Escola Anna Nery, 22 (2). doi: http://doi.org/10.1590/2177-9465-ean-2017-0294

5. Zane, D., Feldman, P. L., Sawyer, T., Sobol, Z., Hawes, J. (2020). Development and Regulatory Challenges for Peptide Therapeutics. International Journal of Toxicology, 40 (2), 108-124. doi: http://doi.org/10.1177/1091581820977846

6. Quinn, T. J. (2019). In people with vascular dementia, does cerebrolysin improve outcomes compared with placebo? Cochrane Clinical Answers. doi: http://doi.org/10.1002/cca.130

7. Khavinson, V. K. (2020). Peptide medicines: past, present, future. Clinical Medicine, 98 (3), 165-177. doi: http://doi.org/10.30629/0023-2149-2020-98-3-165-177

8. Yi, M., Li, H., Wu, Z., Yan, J., Liu, Q., Ou, C., Chen, M. (2017). A Promising Therapeutic Target for Metabolic Diseases: Neuropeptide Y Receptors in Humans. Cellular Physiology and Biochemistry, 45 (1), 88-107. doi: http://doi.org/10.1159/000486225

9. Méndez-Couz, M., Manahan-Vaughan, D., Silva, A. P., González-Pardo, H., Arias, J. L., Conejo, N. M. (2021). Metaplastic contribution of neuropeptide Y receptors to spatial memory acquisition. Behavioural Brain Research, 396. doi: http://doi.org/10.1016/ j.bbr.2020.112864

10. Gøtzsche, C. R., Woldbye, D. P. D. (2016). The role of NPY in learning and memory. Neuropeptides, 55, 79-89. doi: http://doi.org/10.1016/j.npep.2015.09.010

11. Lach, G., de Lima, T. C. M. (2013). Role of NPY Y1 receptor on acquisition, consolidation and extinction on contextual fear conditioning: Dissociation between anxiety, locomotion and non-emotional memory behavior. Neurobiology of Learning and Memory, 103, 26-33. doi: http://doi.org/10.1016/j.nlm.2013.04.005

12. Kornhuber, J., Zoicas, I. (2019). Neuropeptide Y reduces expression of social fear via simultaneous activation of Y1 and Y2 receptors. Journal of Psychopharmacology, 33 (12), 1533-1539. doi: http://doi.org/10.1177/0269881119862529

13. Kornhuber, J., Zoicas, I. (2017). Neuropeptide Y prolongs non-social memory and differentially affects acquisition, consolidation, and retrieval of non-social and social memory in male mice. Scientific Reports, 7 (1). doi: http://doi.org/10.1038/s41598-017-07273-x

14. Rangani, R., Upadhya, M., Nakhate, K., Kokare, D., Subhedar, N. (2012). Nicotine evoked improvement in learning and memory is mediated through NPY Y1 receptors in rat model of Alzheimer's disease. Peptides, 33 (2), 317-328. doi: http://doi.org/10.1016/ j.peptides.2012.01.004

15. Flood, J. F., Hernandez, E. N., Morley, J. E. (1987). Modulation of memory processing by neuropeptide Y. Brain Research, 421 (1-2), 280-290. doi: http://doi.org/10.1016/0006-8993(87)91297-2

16. Bouchard, P., Maurice, T., St-Pierre, S., Privat, A., Quirion, R. (1997). Neuropeptide Y and the Calcitonin Gene-related Peptide Attenuate Learning Impairments Induced by MK-801 via a Sigma Receptor-related mechanism. European Journal of Neuroscience, 9 (10), 2142-2151. doi: http://doi.org/10.1111/j.1460-9568.1997.tb01381.x

17. Brothers, S. P., Wahlestedt, C. (2010). Therapeutic potential of neuropeptide Y (NPY) receptor ligands. EMBO Molecular Medicine, 2 (11), 429-439. doi: http://doi.org/10.1002/emmm.201000100

18. Pedragosa-Badia, X., Stichel, J., Beck-Sickinger, A. G. (2013). Neuropeptide Y receptors: how to get subtype selectivity. Frontiers in Endocrinology, 4. doi: http://doi.org/10.3389/fendo.2013.00005

19. Di, L. (2014). Strategic Approaches to Optimizing Peptide ADME Properties. The AAPS Journal, 17 (1), 134-143. doi: http://doi.org/10.1208/s12248-014-9687-3

20. Zagayko, A. L., Havrylov, I. O., Lytkin, D. V. (2019). The study of the effect of the low molecular analog of neuropeptide Y on behavioral reactions in rats. Clinical Pharmacy, 23 (4), 30-36. doi: http://doi.org/10.24959/cphj.19.1509

21. Havrylov, I. O., Shtrygol, S. Yu. (2021). Investigation of the effect of a modified fragment of neuropeptide Y on memory phases and extrapolation escape of animals. Česká a Slovenská Farmacie, 70 (3), 91-99. doi: http://doi.org/10.5817/csf2021-3-91 
22. Sabban, E. L., Alaluf, L. G., Serova, L. I. (2016). Potential of neuropeptide Y for preventing or treating post-traumatic stress disorder. Neuropeptides, 56, 19-24. doi: http://doi.org/10.1016/j.npep.2015.11.004

23. Meredith, M. E., Salameh, T. S., Banks, W. A. (2015). Intranasal Delivery of Proteins and Peptides in the Treatment of Neurodegenerative Diseases. The AAPS Journal, 17 (4), 780-787. doi: http://doi.org/10.1208/s12248-015-9719-7

24. Mironov, A. V. (2012). Rukovodstvo po provedeniiu doklinicheskikh issledovanii lekarstvennykh veschestv. Part. 1. Moscow: Grif i K, 944.

25. Garthe, A., Kempermann, G. (2013). An old test for new neurons: refining the Morris water maze to study the functional relevance of adult hippocampal neurogenesis. Frontiers in Neuroscience, 7. doi: http://doi.org/10.3389/fnins.2013.00063

26. Nunez, J. (2008). Morris Water Maze Experiment. Journal of Visualized Experiments, 19. doi: http://doi.org/10.3791/897

27. Koroleva, S. V., Myasoedov, N. F. (2018). Semax as a Universal Drug for Therapy and Research. Biology Bulletin, 45 (6), 589-600. doi: http://doi.org/10.1134/s1062359018060055

28. Kallupi, M., Vendruscolo, L. F., Carmichael, C. Y., George, O., Koob, G. F., Gilpin, N. W. (2013). Neuropeptide Y Y2R blockade in the central amygdala reduces anxiety-like behavior but not alcohol drinking in alcohol-dependent rats. Addiction Biology, 19 (5), 755-757. doi: http://doi.org/10.1111/adb.12059

Received date 10.12.2021

Accepted date 21.02.2022

Published date 28.02.2022

Ihnat Havrylov*, Department of Pharmacology and Pharmacotherapy, National University of Pharmacy, Pushkinska str., 53, Kharkiv, Ukraine, 61002

Sergey Shtrygol', Doctor of Medical Science, Professor, Department of Pharmacology and Pharmacotherapy, National University of Pharmacy, Pushkinska str., 53, Kharkiv, Ukraine, 61002

Dmytryi Kavraiskyi, PhD, Assistant, Department of Pharmacy Organization and Economics, Bogomolets National Medical University, Shevchenko blvd., 13, Kyiv, Ukraine, 01601

*Corresponding author: Ihnat Havrylov, e-mail: gavrilov.i.ok@gmail.com 